\title{
A New Method to Determine Biot's Coefficients of Bakken Samples
}

Jun He, University of North Dakota, Grand Forks, North Dakota, United States

Zhenhua Rui, Independent Project Analysis, Inc., Ashburn, Virginia, United States

Kegang Ling, University of North Dakota, Grand Forks, North Dakota, United States

Corresponding Author: Zhenhua Rui

Corresponding Author Email: zhenhuarui@gmail.com

Keywords: Biot's Coefficient, Tight Reservoir, Unconventional Resource

\begin{abstract}
In recent years, the development of oil and gas from shale has proceeded quickly in the world through the use of multistage fracturing technology in horizontal well. However, without the knowledge of rock poroelastic characteristics, the successful rate of hydraulic fracturing will be low. Among those poroelastic characteristics, effective stress is required for creating artificial fractures in the shale formation. In this study a new method is proposed to measure the Biot's coefficient, which is one of the key poroelastic parameters for calculating the effective stress.

The Biot's coefficient is obtained after the variations of both the confining and the pore pressures are recorded with a simplified measuring procedures. The Bakken shale samples from Williston Basin are tested. The experiment results show that the Biot's coefficient of Bakken samples obtained from horizontal drilling and vertical drilling are significantly different from each other. This provides a solid base to scientists and engineers for Bakken in-situ stress analysis during multistage hydraulic fracturing and reservoir depletion due to production.
\end{abstract}

\section{Introduction}

In recent years, the development of oil and gas from shale has proceeded quickly in the world through the use of multistage fracturing technology in horizontal well. By creating the fractures to enlarge the stimulated reservoir 
volume, hydraulic fracturing is one of the most important completion techniques for improving the oil and gas production from unconventional resources. It is imperative to study the poroelastic characteristics of the rock to better understand and model the performance of rock under in-situ conditions, thus ensure the success of hydraulic fracturing.

The effective stress [1, 2, and 3] is one of the key concepts for better understanding rock poroealstic characteristics, which consist both the elastic properties [4] and the fracture properties [5, 6, and 7]. It is noted that pore pressure helps counteract the mechanical stress carried through grain-to-grain contact. The relationship is:

$$
\sigma^{\prime}=\sigma-\alpha P_{p}
$$

where $\sigma^{\prime}$ is the stress carried by the matrix called effective stress; $P_{p}$ is the stress carried by pore fluid called pore pressure; $\sigma$ is the total stress; and $\alpha$ is a constant called Biot's coefficient.

Based on the concept of effective stress, many methods have been presented to improve the accuracy and efficiency of the Biot's coefficient measurement, since it is the key factor to accurately calculate effective stress.

Geertsma [8] and Skempton [9] presented a conventional technique to calculate Biot's coefficient by using equation:

$$
\alpha=1-\frac{K}{K_{s}}
$$

where $K$ is the bulk modulus of the rock and $K_{s}$ is the matrix bulk modulus of the rock. Bulk modulus of the rock and matrix bulk modulus of the rock are measured in two different experiments. In the first experiment, $K$ is obtained by setting the pore pressure to zero; and in the second experiment, $K_{s}$ is obtained by setting the pore pressure and confining pressure equal to each other. Azeemuddin [10] improved this technique by measuring $K$ and $K s$ with 'static' and 'dynamics' methods. According to Eqs. 1 and 2, if the rock stiffness is near the matrix bulk modulus, the Biot's coefficient approaches zero and the pore pressure has no impact on the effective stress.

Franquet [11] proposed a technique to measure Biot's coefficient using equation:

$$
\alpha=\frac{\Delta V_{p}}{\Delta V}
$$

where $\Delta V_{p}$ is the variation of the pore volume, and $\Delta V$ is the variation of the total rock volume. Because these parameters are evaluated through measuring the amount of fluid volume drained from the rock sample, an accurate pore volume measurement is needed. To test tight rock sample this method is unacceptable. Firstly, it is difficult to measure the fluid volume because the fluid used for tight rock is gas instead of liquid due to the low permeability of the sample; secondly gas leakage will be likely in this method during the long operating time. Franquet [11] also 
developed a "Mohr envelope" method to calculate the Biot's coefficient. However, serval tests are needed in his method to define the Mohr envelope.

Qiao [12] determined the Biot's coefficient under the assumption that the permeability follows the effective- stress law. The Biot's coefficient is calculated from the variation of permeability due to the change in pore pressure or confining pressure. However, it is difficult to determine the variation in permeability accurately when the rock is tight.

In this study a new method is proposed. The Biot's coefficient is obtained after the variations of both the confining pressure and the pore pressure are recorded with a simplified measuring procedures. In this method, samples only need to be measured once, which is fewer than conventional methods, whose procedures require multiple tests. Therefore, the measurement time is much shorter in proposed method than in the conventional methods.

\section{Methodology}

To better understand the new method, it is necessary to introduce the derivation of the governing equation. The equation is derived by making the following assumptions: 1) the core is homogeneous, 2) the properties of the rock are constant, and 3) the core and gas flow are isothermal.

The bulk modulus of the rock is the ratio of the change of stress to that of the strain, which can be expressed as:

$$
K=\frac{\Delta \sigma^{\prime}}{\Delta \varepsilon_{v}}
$$

where $\Delta \sigma^{\prime}$ is the variation of the effective stress, and $\Delta \varepsilon v$ is the variation of the volumetric strain $\varepsilon v$. Combining Eq. 4 with Eq. 1 we have:

$$
K=\frac{\Delta \sigma^{\prime}}{\Delta \varepsilon_{v}}=\frac{\Delta\left(\sigma-\alpha P_{p}\right)}{\Delta \varepsilon_{v}}
$$

Rearranging above equation, we get

$$
\alpha=\frac{\Delta \sigma-K \Delta \varepsilon_{v}}{\Delta P_{p}}
$$

Eq. 5 can be simplified if we can set $\Delta \varepsilon_{\mathrm{v}}$ zero. This means the volume of the rock sample is constant. Assuming $K$ is constant, and the change of confining pressure $\Delta \mathrm{P}_{c}$ is the change of total stress, $\Delta \sigma$, since no axial pressure exists. Eq. 5 can be simplified to 


$$
\begin{aligned}
\alpha & =\frac{\Delta \sigma}{\Delta P_{p}} \\
& =\frac{\Delta P_{c}}{\Delta P_{p}}
\end{aligned}
$$

Fig. 1 shows the theoretical procedure. Once the initial equilibrium has been obtained, the pore pressure is increased by $\triangle P P$ at time ' $\mathrm{t} 1$ '. This causes a change in the volumetric strain. The volumetric strain will reverse to its original value at time ' $\mathrm{t} 2$ ' after the confining pressure $P_{c}$ is increased by $\Delta P_{c}$. Finally, the Biot's coefficient can be calculated by the ratio of variation of confining pressure to the change of pore pressure as shown in Eq. 6 .

To investigate the correlation between Biot's coefficient and other petrophysical properties, we also measured sample porosity with gas compression method [13], and sample permeability with unsteady-state flow methods [14].

\section{Equipment and Procedure}

Two challenges arise when performing this experiment: 1) identify whether the sample volume has changed or not during the test; and 2) determine the incremental of confining pressure $\left(\Delta P_{c}\right)$ used to reverse the volumetric strain back to its original value after the pore pressure has been increased by $\triangle P P$.

Both challenges can be overcome with the help of high speed data-acquisition systems, accurate pressure transducers, strain gages, and digital computers.

\subsection{Sample and Equipment}

The tested samples are Bakken shales taken from Williston Basin in North Dakota. The samples are cylindrical shape with a dimension of one inch in diameter and two inches in length. They are covered by copper sheets to make a gas-tight seal on the wall of the sample. Strain gages are used to monitor the variation of the sample volume. Fig. 2 shows that one radial strain gage is attached on one side of the sample, and one axial strain gage is attached on the other side of the sample (Fig. 3). The axial strain $\varepsilon a$, and the radial strain $\varepsilon r$ are measured with these strain gages during the experiment. Based on the definition of strain [7], we have:

$$
\varepsilon_{a}=\frac{\Delta L}{L}
$$




$$
\begin{gathered}
\varepsilon_{r}=\frac{\Delta r}{r} \\
\varepsilon_{v}=\frac{\Delta V}{V}
\end{gathered}
$$

where $L$ is the original length of the sample, $r$ is the original radius of the sample, and $V$ is the original volume of the sample. Since the sample shape is cylindrical, the volumetric strain is expressed as follows:

$$
\varepsilon_{v}=\frac{\Delta V}{V}=\frac{\pi(r+\Delta r)^{2}(L+\Delta L)-\pi r^{2} L}{\pi r^{2} L}
$$

Since the strains are very small comparing with sample radius and length, the high order terms can be neglected and Eqs. 7, 8, and 10 can be combined to obtain the volumetric strain equation:

$$
\varepsilon_{v}=\varepsilon_{a}+2 \varepsilon_{r}
$$

Thus, the first challenge is overcome by using the axial and radial strain gages.

The second challenge can be overcome using Autolab-1500, which is the equipment used in this study. It is a complicated laboratory system with three integrated components:

1. A pressure vessel and four associated pressure intensifiers to generate pressures on the test sample;

2. An electronics console that interfaces with the mechanical system to precisely control the state of pressure and to condition and amplify signals from the transducers and devices measuring force, pressure, displacement, strain, and temperature;

3. A data acquisition system which generates reference signals to control the equipment, to acquire data, and to process the data collected on the experiment.

The schematic diagram of the core holder and hydraulic system is depicted in Fig. 4. One temperature transducer (TT1) is used to measure the temperature. Four pressure transducers, PT1, PT2, PT3, and PT4, are used to measure upstream pore pressure, confining pressure at the flank of the core, downstream pore pressure, and axial pressure at the ends of the core, respectively.

\subsection{Procedure}

The measurement procedure of the Biot's coefficient is as following: 
1). Install the sample into AutoLab-1500

(a) Mount the sample in a core holder with flexible rubber sleeves at both ends of the plug (Fig. 5).

Connect the upstream end-cap to a servo-controlled hydraulic intensifier, which is used to control and monitor the upstream pressure. The downstream pressure at the other end of the sample is monitored by a miniature pressure transducer, which is located in the downstream end-cap.

(b) Put the core holder into the pressure vessel, which is filled with mineral oil, and apply confining pressure to a desired level.

(c) Fill the upstream reservoir with dry nitrogen. Because the permeability of Bakken samples are low, gas is used as the test fluid in the experiment.

(d) Connect the upstream reservoir with the sample to the downstream reservoir.

(e) Increase the upstream pressure to a desired level.

(f) Wait until the equilibrium of the downstream and upstream pressure reached.

2). Configure Autolab-1500 system to the confining pressure self-adjusting mode so that the volumetric strain will keep constant.

3). Increase the upstream pressure to the next level.

4). Wait until both the downstream pressure and the confining pressure reach their new equilibrium.

5). Record the variations of confining pressure and pore pressure, respectively.

6). Repeat 3 to 5 by increasing or decreasing the upstream pressure. Fig. 6 shows one record of the experiments.

7). Remove the sample from the core holder, and disconnect the core from the end-caps.

\section{Experimental Results and Discussion}

The recorded pore pressure, confining pressure, and volumetric strain of one sample in an experiment are illustrated in Fig. 6. Table 1 shows the changes of pore and confining pressures to maintain constant volumetric strain. After the pre-equilibrium was achieved at pore pressure of $6.2 \mathrm{MPa}$ and confining pressure of $22.87 \mathrm{MPa}$, the pore pressure was increased to $8.20,10.20$, and $12.30 \mathrm{MPa}$. To restore the sample back to the original condition, the confining pressure is increased to 24.27, 25.77, and 2.09 $\mathrm{MPa}$. The increases in confining pressure were done 
automatically by Autolab-1500. The Biot's coefficient of the sample then was obtained by Eq. 6. The average Biot's coefficient of the sample is 0.69 .

In this study, we have measured the Biot's coefficients of 27 Bakken samples using the proposed method (Table 2). To investigate the heterogeneity of Bakken formation, we tested 10 vertical direction samples (V-sample, taken perpendicular to the bedding) and 17 horizontal direction samples (H-sample, taken along the bedding plane).

The comparison of H-samples to V-samples is shown in Fig. 7. One can observe that the average Biot's coefficient of H-samples (0.67) is larger than that of V-samples (0.61). Figs. 7, 8, and 9 indicate that Biot's coefficient of most H-samples are higher than those of V-samples. This anisotropy of Biot's coefficient of Bakken rock indicates that the Bakken formation is heterogeneous. It means that the influence of the pore pressure to the insitu stress is greater along the bedding plane than perpendicular to the bedding. To evaluate the accuracy of the proposed method, we compare the Biot's coefficient obtained from this study with Havens' results [15]. The comparison indicates that the range of Biot's coefficient in this investigation agrees with that of Havens' study.

Fig. 8 relates the Biot's coefficient to permeability for Bakken samples. The correlations for H-sample and Vsample are:

$$
\begin{aligned}
& H: \alpha=0.6774+0.01121 \cdot \log _{10}(k) \\
& V: \alpha=0.6099+0.00523 \cdot \log _{10}(k)
\end{aligned}
$$

But the relationship between Biot's coefficient and permeability is weak, the R-squared values of the above regression equations are $6.07 \%$ and $1.39 \%$ for $\mathrm{H}$-sample and $\mathrm{V}$-sample, respectively. The weak correlations between Biot's coefficient and permeability is due to the fractures development in some of the core samples. Fractures have been observed in some of Bakken samples used in this study. Simple to complex fracture systems existing in these samples influence the relationship between Biot's coefficient and permeability. Core plugs with fractures have correlation that is quite different from those without fracture. Core plugs with simple fracture system also have correlation that is more or less different from those with complex fracture. Therefore, it is not surprised that a weak correlation was observed. To characterize fracture system in the rock, it is recommend that imaging technologies such as scanning electron microscope (SEM), computed tomography (CT), and nuclear magnetic resonance (NMR) spectroscopy should be conducted in future study. With available digitalized rock information, one can classify core samples into different categories according to the development of fracture system. Then it is expected to observe good correlations between Biot's coefficient and permeability for the same category because the heterogeneity effect has 
been reduced significantly. Therefore, digitalizing rock to characterize pore and fracture distribution is one of the most important tasks in future study.

Fig. 9 shows that Biot's coefficient cannot be related to porosity well for Bakken formation. The reason could be that the porosity of Bakken samples is very low and the change of porosity does not impact Biot's coefficient significantly. It should be noted that Biot's coefficient is a function of rock type, textural of rock, effective porosity, pore throat size, geometry of the pore, and connection and distribution of pores. Therefore, to quantify Biot's coefficient as a function of those parameters, further studies such as SEM, CT, and NMR spectroscopy should be conducted to develop correlations to estimate Biot's coefficient given rock type, textural of rock, effective porosity, pore throat size, geometry of the pore, and connection and distribution of pores.

\section{Conclusions}

In this study, we have presented a new method to measure the Biot's coefficient. It indicated that the Biot's coefficient can be obtained by the ratio of variation of the confining pressure to variation of the pore pressure under constant volumetric strain. We tested the Biot's coefficient for the Bakken samples which are taken along the two principal directions: horizontal samples parallel to the bedding and vertical samples perpendicular to the bedding. The Biot's coefficient of horizontal samples is higher than that of vertical samples. The Biot's coefficient has weak correlations with permeability due to the high heterogeneity resulting from fracture systems. No relationship between Biot's coefficient and porosity was found.

\section{Acknowledgment}

The authors are grateful to The Petroleum Engineering Department of University of North Dakota. This research is supported in part by the U.S. Department of Energy (DOE) under award number DE-FC26-08NT0005643 and North Dakota EPSCoR Program under award number EPS-0814442. The authors would like to thank the Wilson M. Laird Core and Sample Library and the North Dakota Geological Survey for providing core samples for this study.

\section{Nomenclature}




$$
\begin{aligned}
& \mathrm{K} \quad \text { =bulk modulus of the rock } \\
& \mathrm{K}_{\mathrm{s}} \quad=\text { matrix modulus of the rock } \\
& \text { L =original length of the sample } \\
& \mathrm{P}_{\mathrm{c}} \quad=\text { confining pressure } \\
& \mathrm{Pp}_{\mathrm{p}} \quad \text { =pore pressure } \\
& \text { R2 =coefficient of determination } \\
& \mathrm{k} \quad=\text { permeability } \\
& \mathrm{r} \quad=\text { original radius of the sample } \\
& \Delta \mathrm{L} \quad=\text { variation of sample length } \\
& \Delta \mathrm{Pc}_{\mathrm{c}} \quad \text { =variation of the confining pressure } \\
& \Delta \mathrm{P}_{\mathrm{p}} \quad=\text { variation of the pore pressure } \\
& \Delta \mathrm{V} \quad=\text { variation of the total rock volume } \\
& \Delta \mathrm{V}_{\mathrm{p}} \quad=\text { variation of the pore volume } \\
& \Delta \sigma^{\prime} \quad=\text { variation of the effective stress } \\
& \Delta \varepsilon_{\mathrm{v}} \quad=\text { variation of the volumetric strain } \\
& \Delta \mathrm{r} \quad=\text { variation of sample radius } \\
& \alpha \quad=\text { Biot's coefficient } \\
& \varphi \quad \text { =porosity } \\
& \sigma \quad=\text { total stress } \\
& \sigma^{\prime} \quad=\text { effective stress } \\
& \varepsilon a \quad=\text { axial strain } \\
& \text { Er } \quad=\text { radius strain } \\
& \varepsilon_{\mathrm{v}} \quad=\text { volumetric strain }
\end{aligned}
$$

\section{References}

[1]. K. Terzaghi, 1936. The shearing resistance of saturated soil, Proceeding of the First International Conference in Soil Mechanics V1 (1936) 54-56.

[2]. K. Terzaghi, 1943. Theoretical soil mechanics, J. Wiley \& Sons, inc., 1943. 
[3]. M. A. Biot, 1941. General theory of three-dimensional consolidation, J. appl. Physics, Lancaster Pa., 12 (1941) $155-164$.

[4]. A. Nur and J. D. Byerlee, 1971. An exact effective stress law for elastic deformation of rock with fluids, Journal of Geophysical Research V76 (26) (1971) 6414-6419. URL http://dx.doi.org/10.1029/JB076i026p06414

[5]. W. F. Brace and R. J. Martin, 1968. A test of the law of effective stress for crystalline rock of low porosity, International Journal of Rock Mechanics and Mining Science V5 (5) (1968) 415-426.

[6]. M. Bruno and F. Nakagawa, 1991. Pore pressure influence on tensile fracture propagation in sedimentary rock V28 (4) (1991) 261-273.

[7]. J. C. Jaeger, N. G. W. Cook, and R. Zimmerman, 2007. Fundamentals of Rock Mechanics, Wiley, 2007.

[8]. J. Geertsma, 1957. The Effect of Fluid Pressure Decline on Volumetric Changes of Porous Rocks. Society of Petroleum Engineers.

[9]. A. Skempton, 1961. Effective stress in soil, concrete and rocks, Pore Pressure and Suction in Soils (1961) 4-16.

[10]. M. Azeemuddin, K. Khan, M. N. Khan, A. Abdulraheem, Z. Rahim, and M. Y. Al-Qahtani, 2002. Experimental determination of elastic anisotropy and Biot's constant in a Saudi Arabian reservoir sandstone, Society of Petroleum Engineers.

[11]. J. A. S. Franquet and H. H. S. Abass, 1999. Experimental evaluation of Biot's poroelastic parameter by three different methods, ARMA.

[12]. L. P. Qiao, R. C. K. Wong, R. Aguilera, and A. Kantzas, 2012. Determination of Biot's effective-stress coefficient for permeability of Nikanassin sandstone, Journal of Canadian Petroleum Technology.

[13].J. He, P. Pei, K. Ling, Z. Zeng, and H. Liu. 2013. Quantification of rock porosity changes before and after freezing, Journal of Petroleum Science Research 2013.

[14].K. Ling, J. He, P. Pei, G. Han, and H. Zhang, 2013. Determining the Permeability of Tight Rock with Gas Transient Flo, Journal of Natural Gas Science \& Engineering. Vol.15, November 2013

[15].Havens, J. 2007. Mechanical Properties of the Bakken Formation, Master thesis, Colorado School of Mines, Golden, Colorado. 
Table 1: Biot's coefficient test on one Bakken sample (ID\# 20)

\begin{tabular}{|c|c|c|c|c|}
\hline $\begin{array}{c}\text { Pore Pressure } \\
{[\mathrm{MP} \text { a] }}\end{array}$ & \multicolumn{2}{|c|}{$\begin{array}{c}\text { Confining Pressure } \\
{[\mathrm{MP} \text { a }]}\end{array}$} & $\begin{array}{c}\text { Biot's } \\
\text { Coefficient }\end{array}$ \\
\cline { 1 - 4 } from & to & from & to & \\
\hline 6.20 & 8.20 & 22.87 & 24.27 & 0.70 \\
\hline 8.20 & 10.20 & 24.27 & 25.77 & 0.75 \\
\hline 10.20 & 12.30 & 25.77 & 27.09 & 0.63 \\
\hline \multicolumn{4}{|c|}{ Average } & 0.69 \\
\hline
\end{tabular}

Table 2: The results of Biot's coefficient test

\begin{tabular}{|c|c|c|c|c|}
\hline $\begin{array}{c}\text { Sample } \\
\text { ID }\end{array}$ & $\begin{array}{c}\text { Permeability } \\
\mathrm{k}:(\mu \mathrm{D})\end{array}$ & $\begin{array}{c}\text { Porosity } \\
\varphi:(\%)\end{array}$ & Direction & $\begin{array}{c}\text { Biot's } \\
\text { Coefficient }\end{array}$ \\
\hline 1 & 3.73 & 4.62 & $\mathrm{~V}$ & 0.65 \\
\hline 2 & 0.08 & 5.73 & $\mathrm{~V}$ & 0.66 \\
\hline 3 & 0.05 & 5.76 & $\mathrm{~V}$ & 0.60 \\
\hline 4 & 0.07 & 4.19 & $\mathrm{~V}$ & 0.57 \\
\hline 5 & 0.24 & 4.03 & $\mathrm{~V}$ & 0.61 \\
\hline 6 & 0.20 & 3.58 & $\mathrm{~V}$ & 0.59 \\
\hline 7 & 2.19 & 5.61 & $\mathrm{~V}$ & 0.58 \\
\hline 8 & 0.19 & 5.57 & $\mathrm{~V}$ & 0.61 \\
\hline 9 & 1.45 & 5.93 & $\mathrm{~V}$ & 0.63 \\
\hline 10 & 1.54 & 5.34 & $\mathrm{~V}$ & 0.58 \\
\hline 11 & 0.64 & 4.30 & $\mathrm{H}$ & 0.67 \\
\hline 12 & 0.14 & 4.56 & $\mathrm{H}$ & 0.70 \\
\hline 13 & 0.09 & 3.47 & $\mathrm{H}$ & 0.59 \\
\hline 14 & 0.40 & 4.93 & $\mathrm{H}$ & 0.67 \\
\hline 15 & 0.08 & 3.97 & $\mathrm{H}$ & 0.68 \\
\hline 16 & 0.07 & 4.18 & $\mathrm{H}$ & 0.66 \\
\hline 17 & 0.33 & 4.59 & $\mathrm{H}$ & 0.70 \\
\hline 18 & 1.17 & 2.23 & $\mathrm{H}$ & 0.69 \\
\hline 19 & 1.60 & 5.46 & $\mathrm{H}$ & 0.68 \\
\hline 20 & 4.68 & 7.26 & $\mathrm{H}$ & 0.69 \\
\hline 21 & 0.09 & 5.45 & $\mathrm{H}$ & 0.67 \\
\hline 22 & 1.60 & 2.39 & $\mathrm{H}$ & 0.67 \\
\hline 23 & 1.58 & 2.39 & $\mathrm{H}$ & 0.67 \\
\hline 24 & 1.44 & 2.39 & $\mathrm{H}$ & 0.67 \\
\hline 25 & 1.39 & 2.39 & $\mathrm{H}$ & 0.67 \\
\hline 26 & 0.71 & 6.01 & $\mathrm{H}$ & 0.68 \\
\hline 27 & 0.23 & 5.18 & $\mathrm{H}$ & 0.70 \\
\hline
\end{tabular}




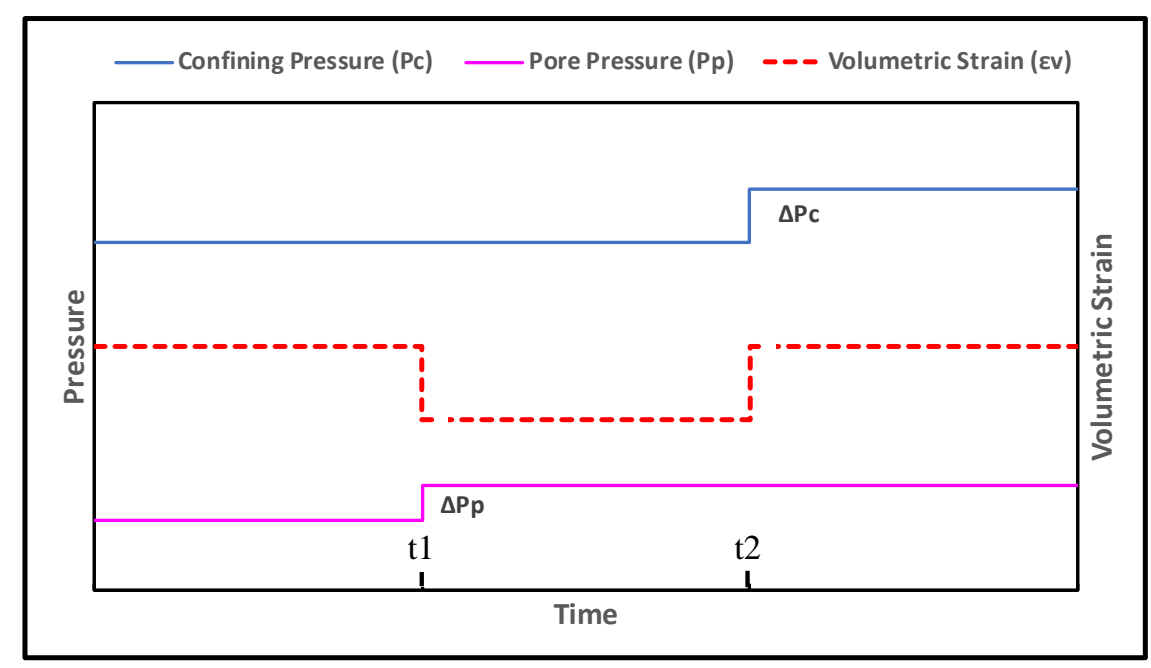

Figure 1: Schematic diagram of Biot's coefficient measuring process

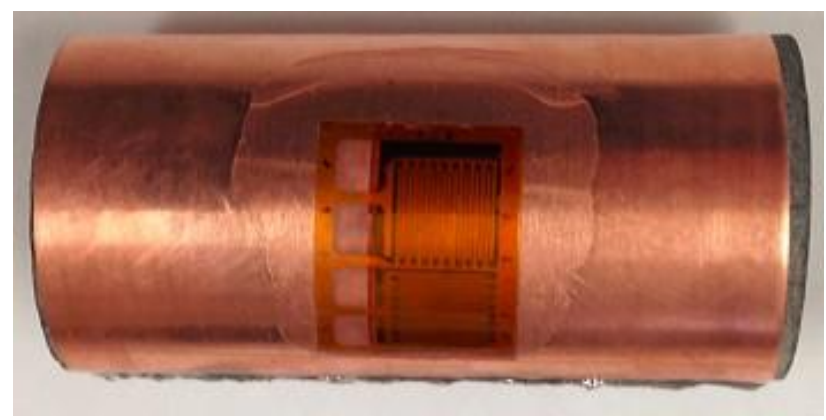

Figure 2: Image of sample with radial strain gages

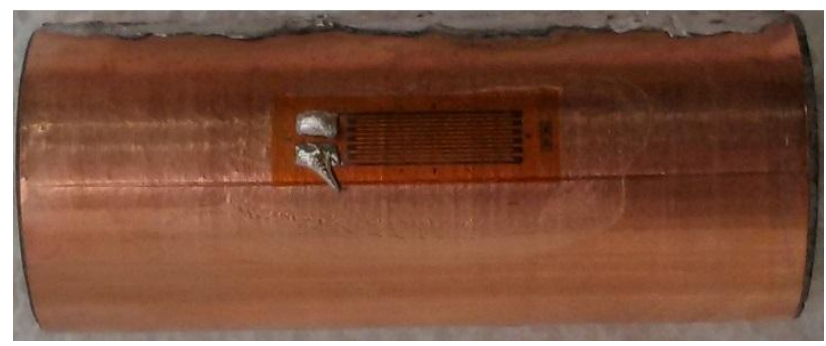

Figure 3: Image of sample with axial strain gage 


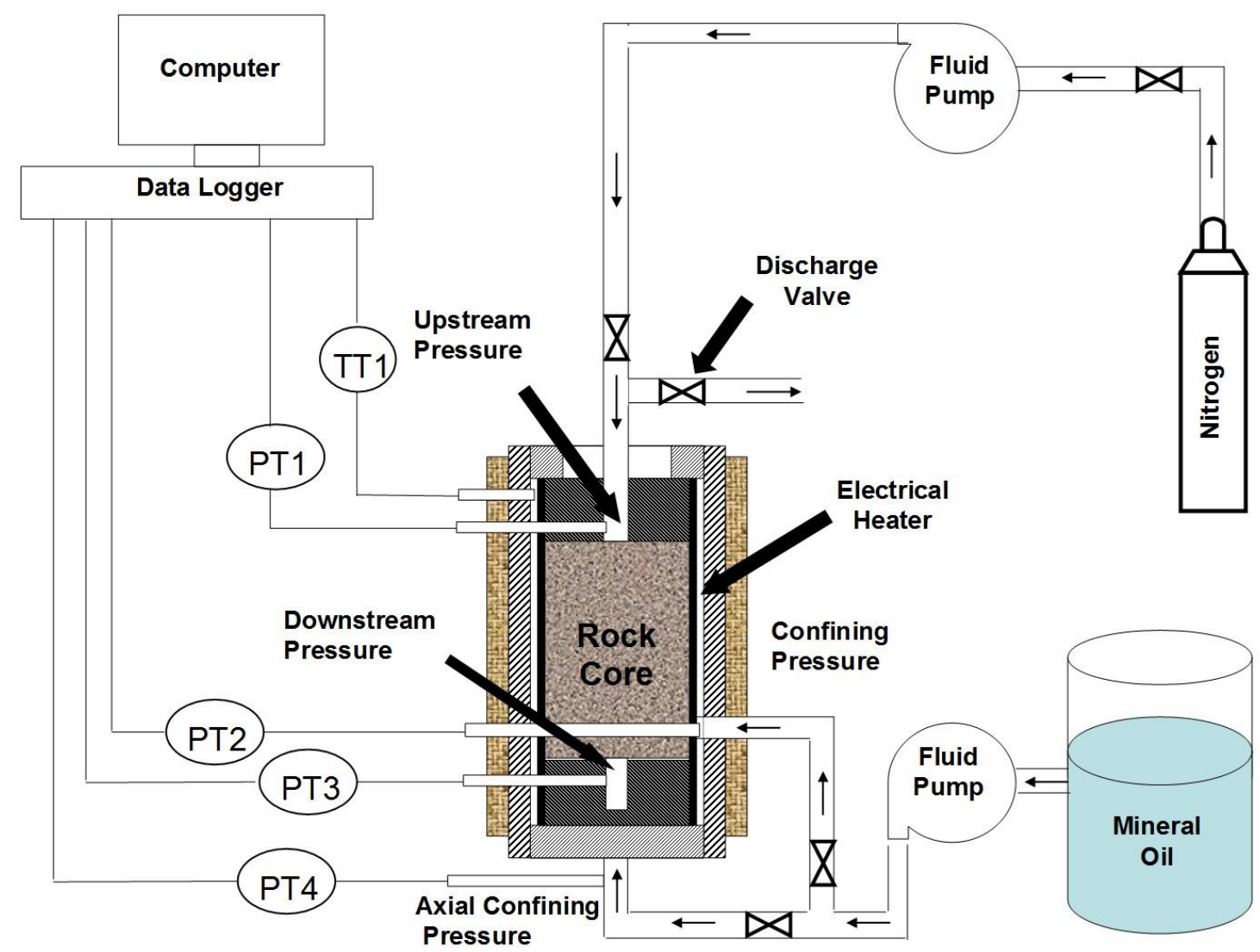

Figure 4: The schematic diagram of the core holder and hydraulic system in the equipment (Autolab-1500) [14]

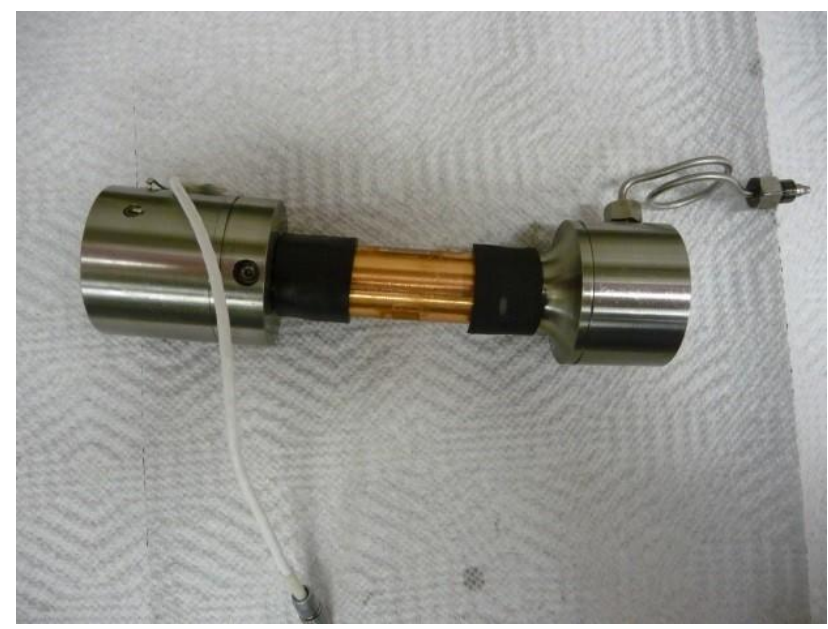

Figure 5: Image of the sample connected to the end caps 


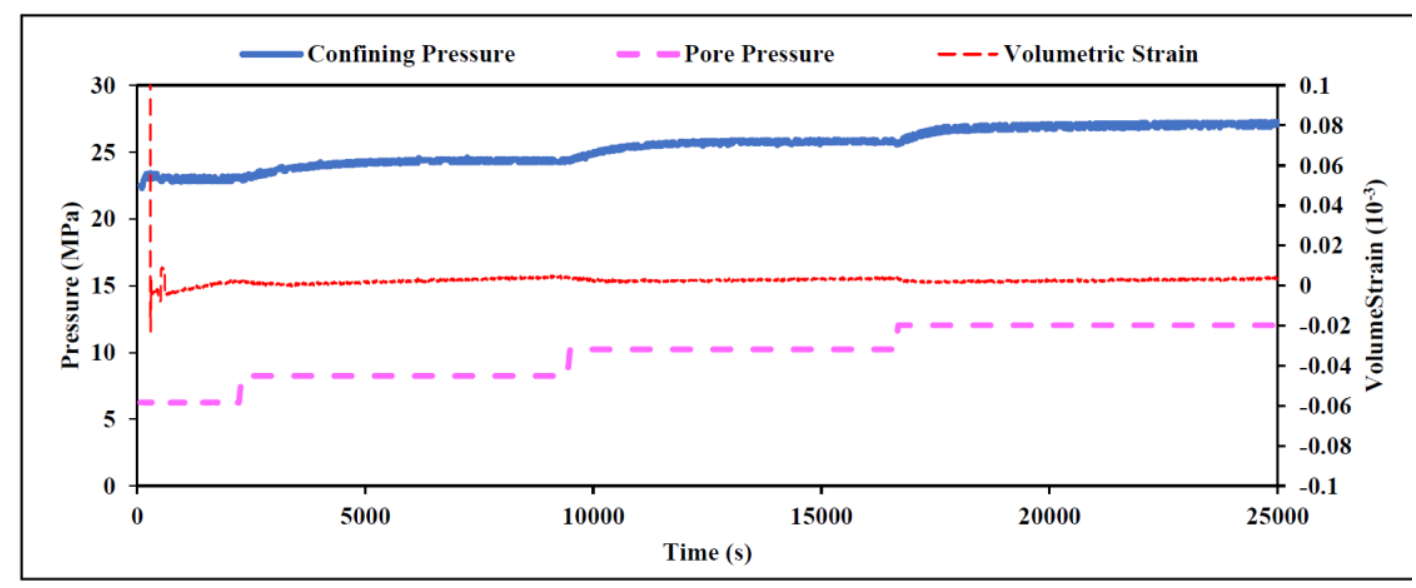

Figure 6: The recording curves in one experiment

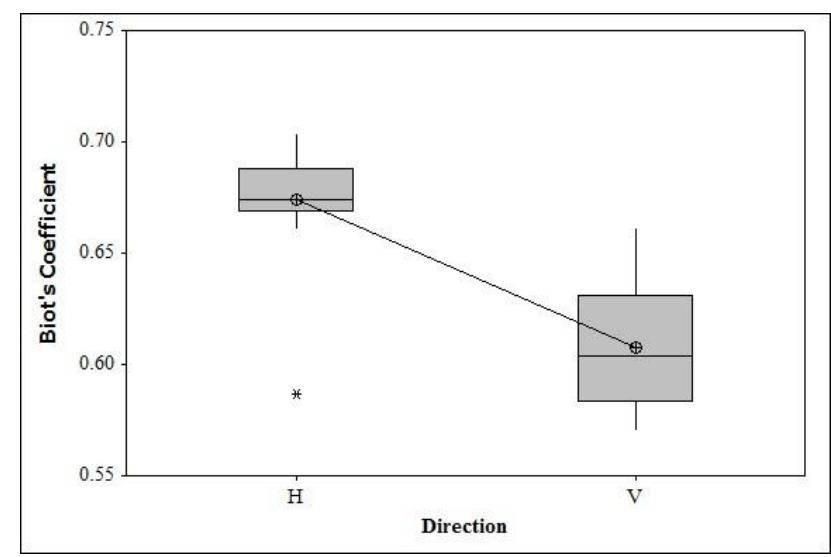

Figure 7: The Box Plot of Biot's Coefficient with two groups (horizontal sample and vertical sample)

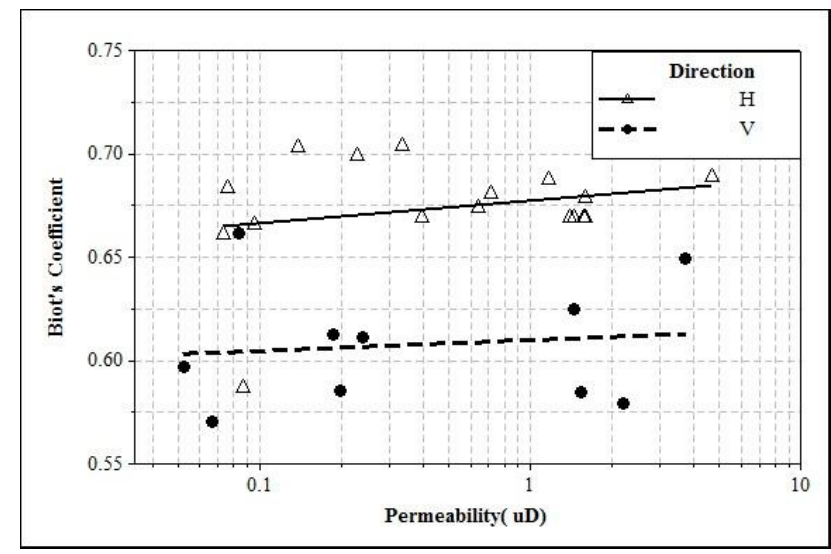

Figure 8: Biot's coefficient vs. Permeability 


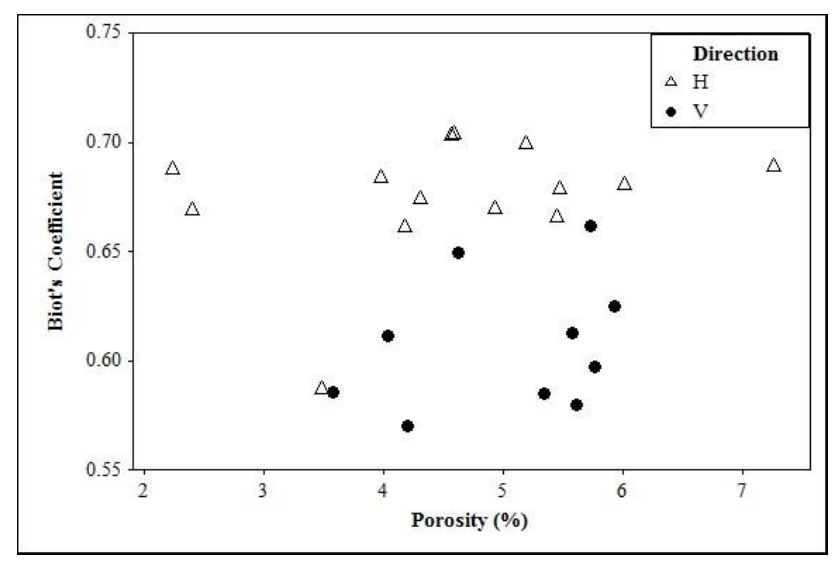

Figure 9: Bit's coefficient vs. Porosity

15 